\title{
Novos tempos de consolidação dos direitos sociais e seus reflexos na ação pedagógica.
}

Maria Alcina Ramos de Freitas*

Resumo: Este artigo é parte de uma pesquisa que teve como objetivo conhecer os processos através dos quais se produz, na escola, a homofobia. Os estudos sobre homossexualidades no ambiente escolar consideram a atuação das/os educadoras/es na esfera pública estadual. A etapa, aqui descrita, estuda a consolidação dos direitos sociais e seus reflexos na ação pedagógica. A escola, que tem como papel fundamental o processo de socialização comprometido com o incentivo ao respeito e a percepção positiva da diversidade humana, ainda não sabe lidar com a homofobia. É imprescindível que sejam oferecidas aos profissionais de educação oportunidades de repensar conceitos a respeito de tabus, valores, costumes e convicções que possam existir sobre a sexualidade, aliados ao entendimento dos mecanismos de dominação e, nesse processo, a importância que o estudo qualificado tem na percepção da fluidez das linhas imaginárias em relação às fronteiras do gênero e dos desejos sexuais.

Palavras-chave: direitos sociais, práticas pedagógicas, homofobia.

Abstract: This article is part of a research aimed to understand the processes by which it produces, in high school, homophobia. Studies on homosexuality at school consider the performance of the educators in the public education. The step described in this article focus on the consolidation of social rights and his reflections on pedagogical action. The school, which has the key role the socialization process committed to encouraging respect and positive perception of human diversity, yet don't know how to deal with homophobia. It is imperative that are offered to educators opportunities to rethink concepts about taboos, values, customs and beliefs that may exist on sexuality. It's important to understand of the mechanisms of domination and, in the process, the importance that the research has in perception of the fluidity of the imaginary lines in relation to the boundaries of gender and sexual desires.

Keywords: social rights; pedagogical practices; homophobia

\footnotetext{
* Mestra em Educação Brasileira; Funcionária Pública Estadual lotada na Secretaria Estadual de Educação de Alagoas/Gerência de Diversidades/Superintendência de Políticas Educacionais; contato: cinaal@gmail.com
}

Latitude, Vol. 07, no 1, pp. 53-59, 2013 
Maria Alcina Ramos de Freitas

Gostaria de iniciar agradecendo ao convite bem como as indicações ao meu trabalho. Desejo ao recém-nascido Núcleo de Pesquisas em Gênero, Saúde e Direitos Humanos - Mandacaru - do Programa de Pós Graduação em Sociologia, muito trabalho e que assim como essa planta oriunda das terras áridas e quentes do nordeste, possa contribuir aplacando a sede de um povo que resiste e sofre vítima da sua cultura machista, heterossexista, racista cujo comportamento ainda traz ranços do cangaço.

Sobre o tema dessa mesa: pesquisa social e construção de políticas públicas nos campos de saúde, educação e combate a violência, nosso ponto de partida são os novos tempos de consolidação dos direitos sociais e seus reflexos na ação pedagógica.

Há a necessidade de a escola pública ocupar o espaço de mediação e de acolhimento, das múltiplas identidades presentes no cotidiano escolar. As relações no interior da escola, na maioria das vezes, não favorecem a construção plural do sujeito e a criação de vínculos afetivos positivos para as pessoas que não estão circunscritos aos padrões de comportamento exigidos. As relações de amizade e confiança estabelecidas na escola fazem parte da construção da subjetividade do ser humano. As dificuldades de compreensão e superação do preconceito e da discriminação da comunidade escolar promovem um ambiente excludente e ameaçador que interfere diretamente na constituição das identidades. Essa realidade pode ser observada inclusive em pesquisas, uma vez que o comportamento de imposição de uma única identidade sexual e de gênero em sintonia com o sexo biológico faz com que muitas pessoas sofram discriminação, humilhação e sintam-se, muitas vezes, incapazes de reagir diante das situações de agressão e violência. Por conta disso, um número significativo de pessoas, que ocupam as salas de aula, empurrados pela exclusão, passa a ocupar espaços marginais, na tentativa de compreender e poder expressar sua condição percebida como diferenciada. Ou ainda, o que é mais comum, abandone a escola - pela negação do seu direito constitucional - não restando muitas opções além de subempregos, espaços de violência e mais exclusão.

Ao se abordar a temática das sexualidades, como lugar de diversidade e possibilidades como direito individual e subjetivo, observamos uma espécie de medo, de inquietação. Nesse contexto, a manifestação de simpatia ou a simples proximidade solidária, fazem emergir espaços de controle social, expressos em piadinhas, dúvidas com relação à sexualidade, entre tantos outros mecanismos de exclusão, vivenciados e expressos no cotidiano que atuam como um rolo compressor na estima das/os estudantes. Com relação aos currículos, base da ação pedagógica, percebemos que seus conteúdos são desenvolvidos de forma explícita na maioria das instituições escolares e aquilo que é enfatizado nas propostas curriculares, chama atenção para a arrasadora presença das culturas que podemos chamar de hegemônicas.

As culturas ou vozes dos grupos sociais minoritários e/ou marginalizados que não dispõem de estruturas importantes de poder costumam ser silenciadas, quando não estereotipadas e deformadas, para anular suas possibilidades de reação (SANTOMÉ, 1995, p. 161). Quanto à formação das educadoras e educadores não podemos esquecer que ainda estão fundamentados em modelos de 
Novos tempos de consolidação dos direitos sociais e seus reflexos na ação pedagógica.

socialização profissional que lhe exigiam unicamente prestar atenção à formulação de objetivos e metodologias, não considerando objeto de sua incumbência a seleção explícita dos conteúdos culturais. Essa tradição contribuiu de forma decisiva para deixar em mãos de outras pessoas (em geral, as editoras de livros didáticos) os conteúdos que devem integrar o currículo e, o que é pior, a sua coisificação. Em muitas ocasiões os conteúdos são contemplados pelos estudantes como fórmulas vazias, sem sequer a compreensão de seu sentido. Ao mesmo tempo, se criou uma tradição na qual os conteúdos apresentados nos livros didáticos aparecem como únicos possíveis, os únicos pensáveis (SANTOMÉ, 1995, p. 161).

A escola tem um papel fundamental no processo de socialização. É nela que as pessoas passam grande parte do seu tempo e constroem seus valores sociais. É nesse espaço onde deveria haver o compromisso em incentivar o respeito e a percepção positiva da multiplicidade humana, uma vez que esse ambiente é frequentado por uma vasta diversidade de pessoas, cada qual com suas questões afetivas, sexuais, pensamentos, valores e desejos, oriundas de construções sociais, expressões de várias etnias e contextos sociais, econômicos e culturais. Um ambiente que vai se constituindo plural a partir de cada singularidade das pessoas que o compõe. É imprescindível que sejam oferecidas aos profissionais da educação possibilidades reflexivas a respeito de tabus, valores, costumes e convicções que possam existir sobre a sexualidade.

As instituições escolares são lugares de luta, e a pedagogia pode e tem que dialogar com avanços políticos e culturais. As escolas como instituições de socialização têm como missão expandir as capacidades humanas, favorecer análises e processos de reflexão em comum da realidade, desenvolver nas/os estudantes os procedimentos e destrezas imprescindíveis para sua atuação responsável, crítica, democrática e solidária na sociedade (SANTOMÉ, 1995, p. 175).

Ao se associar a sexualidade apenas à reprodução humana e à prevenção das doenças, sem discutir o prazer, a afetividade, a responsabilidade, os papéis de gênero, entre outros, ficam fora da discussão um número expressivo de pessoas que têm outros focos de interesse, além de ocultar uma realidade que pode ser refletida, por ser muito mais ampla e necessita ser percebida no contexto pedagógico. A escola não pode deixar de contemplar, por exemplo, a realidade de uniões afetivas e sexuais entre pessoas do mesmo sexo e muito menos reconhecer a existência de famílias constituídas pela comunidade LGBT. O ato de pensar criticamente a crise do capital, os efeitos do patriarcado, a colonização dos desejos, e todos seus reflexos, na sociedade atual, entre tantos outros fatores históricos e sociais, apresenta uma nova concepção de educação, que diminui o distanciamento entre o discurso culto da maneira de entender e expressar os problemas da vida cotidiana, facilitando a apreensão e a utilização democrática deste discurso, convertendo-se em recurso de interpretação e ação na vida social cotidiana. A educação formal tem que recuperar uma de suas razões de ser: a de ser um espaço onde as novas gerações se capacitem para adquirir e analisar criticamente o legado cultural da sociedade. As salas de aula não podem continuar sendo um lugar para a memorização de informações descontextualizadas. É preciso que as/os estudantes possam compreender as diferentes concepções do mundo que se ocultam sob cada 
Maria Alcina Ramos de Freitas

uma delas e os principais problemas da sociedade a que pertencem (SANTOMÉ, 1995, p.176).

Pesquisar e analisar o conjunto de fatores plurais que condicionam os processos de ensino-aprendizagem - os ritos, os costumes, as formas de organização do espaço físico, o tempo, o consenso não discutido, o que é prioritário estar no currículo, às ideias onipresentes, os assuntos negados, as expectativas não questionadas, os interesses inegociáveis, os códigos aprendidos e reproduzidos de forma mecânica - são elementos fundamentais que devem ser estudados, compreendidos. Isto deve ser feito para que a prática pedagógica possa dar passos que, aos poucos, constitua espaços mais amplos, que proporcionem aos educadoras/es assumirem um papel construtivo de participação e reflexão. Onde seja possível desenvolver a capacidade da aprendizagem significativa que só é possível por meio da relação, da convivência e da interação de cada pessoa com o resto do grupo. Preparar-se para mudanças e incertezas é fundamental.

Identificamos nas escolas pesquisadas espaços criativos explícitos na ação pedagógica que permitem a visibilidade positiva da orientação afetiva homoerótica, bem como a compreensão que os sentimentos como algo subjetivo e protegido pelo direito constitucional que, portanto, deve ser percebidos com respeito (FREITAS, 2009). A educação pública e laica tem como obrigação privilegiar informações científicas e oportunizar espaços de estudos e formação continuada para desmistificar tabus, preconceitos e discriminação com enfoque nos direitos humanos fundamentados na ética e autoestima.

Observamos ainda vários espaços de ressignificação da concepção docente a respeito de novas posturas em relação à sexualidade e o fazer pedagógico, proporcionando espaços de conflitos e incertezas, que impulsionam reflexões e debates avançando em políticas educacionais que incluam a diversidade humana que compõem as salas de aula.

A partir desses elementos observamos que há possibilidades de surgir a autoprodução, precedida da reflexão contextualizada, cujo um dos propósitos é ampliar a capacidade crítica, em benefício da liberdade além de ampliar a melhoria das condições da vida dos indivíduos dos diversos grupos sociais. É preciso que todas/os profissionais do espaço educativo possam construir propostas alternativas. Uma das maneiras de começar pode ser por meio da construção de materiais curriculares capazes de contribuir para um questionamento das injustiças atuais permeadas pela exclusão e violência que se firmam nas relações sociais de desigualdades e submissão (por exemplo, sexismo, racismo, classismo etc) (SANTOMÉ, 1995, p. 175). Trabalhar com as sexualidades possíveis, próprias de muitos seres humanos, é uma tarefa árdua, graças à ordem estabelecida nas relações de dominação, que preveem direitos e privilégios em detrimento às restrições e submissão vivenciadas no campo dos gêneros. Esse trabalho coletivo de socialização de construção dos gêneros polarizados e bem distanciados entre si produz causas e efeitos expressos inclusive na representação da realidade, conforme destaca Bourdieu (2007). As aparências biológicas e os efeitos, bem reais, que um longo trabalho coletivo definiram a biologização do social e produziu nos corpos e nas mentes características esperadas e marcadas como únicas aceitáveis para cada gênero biológico uma construção social naturalizada (os 'gêneros' como 
Novos tempos de consolidação dos direitos sociais e seus reflexos na ação pedagógica.

habitus sexuados), com o fundamento in natura da arbitrária divisão que está no princípio não só da realidade como também da representação da realidade e que se impõe por vezes à própria pesquisa (BOURDIEU, 2007, p. 9 e 10).

A Escola e ou Estado, segundo Bourdieu (2007, p. 11) são lugares de elaboração e de imposição dos princípios de dominação, que são exercidos dentro de um universo mais privado, e os define como campo de ação que se encontra "aberto às lutas feministas, chamado então a assumir um papel original e bem definido no seio mesmo das lutas políticas contra todas as formas de dominação". Considera ainda, que essa revolução do conhecimento apresentará consequências na prática e, particularmente, na concepção e estratégias de transformação das relações de forças material e simbólica entre os sexos. É necessário possibilitar o conhecimento pelo entendimento dos mecanismos de dominação e a compreensão, pela lógica das práticas dos sujeitos sociais reais, num ambiente desigual e conflituoso, que é o espaço em que nos relacionamos. Os indivíduos que possuem diferentes níveis de acesso aos bens culturais, econômicos e culturais, com base em conceitos sociais construídos que classificam os iguais, com base em uma supremacia de gênero, etnia e credo, convivem e estabelecem regras de convívio. Isso tudo é fundamento, não pode ser desprezado, e, portanto, reafirma a importância desses estudos. É nesse espaço de construção política que a pesquisa acadêmica serve de instrumento para enfrentar os desafios, construir novos espaços de reflexão identitária. São grandes os desafios para dinamizar o cotidiano das escolas, tendo por base as necessidades emergentes e as multiplicidades que ocorrem nas salas de aula; a miserabilidade em que está submetida a maior parte da população alagoana e o número expressivo de excluídos/as da educação dá o tom dessa realidade. Com o auxílio da informação é necessário admitirmos a fluidez das linhas imaginárias que a ideologia burguesa tenta firmar como intransponíveis, em especial nas fronteiras do gênero e dos desejos sexuais.

Consideramos fundamental entender os caminhos históricos e políticos estudados sobre o poder, expressos na sexualidade e hierarquias baseados nos padrões definidos por gênero, que elabora um modelo político de gestão de corpos e desejos, conforme Welzer-Lang (2001), pelo fato de que estes vão assumindo o controle das vidas, inclusive nas escolas. $\mathrm{O}$ poder, nessa perspectiva se expressa com maior ênfase na violência simbólica, é o que lembra Bourdieu (2007), vivida cotidianamente e que se naturaliza e dificultando a compreensão desses espaços normalizadores, expondo vidas.

Acreditamos ser importante entender como o poder, via violência simbólica, exclui e inclui, hierarquiza pessoas e grupos sociais. A violência que é vivenciada e tem a possibilidade de se tornar invisível, até para suas vítimas, se exerce principalmente por meio da comunicação e pela via do conhecimento, transformando o que é social, em natural e biológico.

A escola pública deveria ser um lugar que pressupõe acolhimento e respeito às diversidades. Não poderia privar quem quer que seja do direito à educação. A educação aqui entendida como espaço onde as identidades são sempre relacionais, diz Vieira (2001), que privilegia os processos dialógicos onde a homofobia passa a ser percebida como uma violência autoritária e arbitrária que exclui, oprime e, em muitos casos, mata. 
Maria Alcina Ramos de Freitas

Que o espaço dedicado à educação possa não negar a importância que tem para a diminuição da vulnerabilidade, oriunda da violência homofóbica, os estudos da sexualidade e do poder. Um espaço laico, lugar de vida; de expressões; de lutas; de socialização; percebida como uma das ferramentas para o fim de todas as fobias e, principalmente, espaço capaz de expandir as capacidades humanas.

Ao estudarmos e analisarmos tais fatos, é possível entender, que a sexualidade é uma construção social, histórica e que a forma que percebemos as várias expressões eróticas, tem implicações nas nossas ações no cotidiano escolar. Podemos ensaiar produções de propostas curriculares, para ouvir as denúncias e os anseios. Constituir espaços de estudos onde a liberdade, a criticidade, o respeito, e a valorização do ser humano, e que seus pensamentos possam ser socializados e ouvidos no cotidiano escolar. E, para tanto, é fundamental repensar o currículo que estamos utilizando.

Os temas transversais propostos pelos Parâmetros Curriculares Nacionais, entre eles a orientação sexual, em vigor, silenciam completamente a temática homossexual. O que transparece nitidamente é a heterossexualidade como única possibilidade de viver a sexualidade e os afetos.

Observamos que as práticas de violência simbólica permearam muitas das ações pedagógicas na escola durante o desenvolvimento da pesquisa, como por exemplo, quando as/os professoras/es demonstraram resistência ao nome social; quando apresentam conceitos com base na religiosidade exacerbada, quando reafirmam o papel sexual estabelecido pelo gênero, isto é, papéis definidos para pessoas que nasceram com o sexo biológico masculino e ou feminino, e desconsideram as identidades sexuais enquanto construções sociais e históricas, que revelam como as pessoas se sentem, se apresentam e são reconhecidas por seus pares.

Além da tendência a não perceber a discriminação e a violência contra homossexuais por estarem naturalizadas; do tratamento diferenciado quando se refere aos casais heterossexuais e homossexuais, dado que não se referem a todas/os pesquisadas/os, pois alguns/mas professores/as conseguem perceber as variadas expressões afetivo-sexuais. Esses olhares que tendem a não ver e a não reconhecer a existência das identidades homossexuais nas escolas tendem também a silenciarem frente aos direitos adquiridos por esses grupos.

Esse silenciamento é uma das violências simbólicas mais comuns nas escolas, pois essas posturas permitem que as práticas de discriminação sigam acontecendo. 
Novos tempos de consolidação dos direitos sociais e seus reflexos na ação pedagógica.

\section{Referências}

BOURDIEU, Pierre. A dominação masculina. Trad. Maria Helena Kühner, $5^{\mathbf{a}}$ ed. Rio de Janeiro: Bertrand Brasil, 2007.

FREITAS, Maria Alcina Ramos de. Purpurina na Terra do Cangaço: refletindo a homossexualidade na escola. Maceió, Programa de Pós-Graduação em Educação, UFAL, 2009.

SANTOMÉ, Jurgo Torres. As culturas negadas e silenciadas no currículo. In: SILVA, Tomaz Tadeu da. (org.). Alienígenas na sala de aula. Petrópolis: Vozes, 1995.

VIEIRA, Jarbas Santos. Currículo (rastros, história, blasfêmia, dissoluções, deslizamentos, pistas). Revista Educação. Maceió, ano 9, no 15, Dez, 2001.

WELZER-LANG, Daniel. A construção do masculino: dominação das mulheres e homofobia. Revista de Estudos Feministas, Santa Catarina, ano 9, 2oㅗ semestre, 2001. 